\title{
Intra-Individual and Seasonal Variation of Selected Biomarkers for Internal Load Monitoring in U-19 Soccer Players
}

\author{
Manuel Becker1,2, Billy Sperlich ${ }^{3 *}$, Christoph Zinner ${ }^{4}$ and Silvia Achtzehn ${ }^{5,6}$ \\ ${ }^{1}$ Institute of Exercise Training and Sport Informatics, German Sport University Cologne, Cologne, Germany, ${ }^{2}$ Decode \\ Dynamics Sports Performance Institute, Waldbronn, Germany, ${ }^{3}$ Integrative and Experimental Exercise Science and Training, \\ Institute of Sport Science, University of Würzburg, Würzburg, Germany, ${ }^{4}$ Department of Sport, University of Applied \\ Sciences for Police and Administration of Hesse, Wiesbaden, Germany, ${ }^{5}$ Institute of Cardiology and Sports Medicine, \\ German Sport University Cologne, Cologne, Germany, ${ }^{6}$ The German Research Centre of Elite Sport, German Sport \\ University Cologne, Cologne, Germany
}

\section{OPEN ACCESS}

Edited by:

Luca Paolo Ardigò,

University of Verona, Italy

Reviewed by:

Olaf Prieske,

University of Applied Sciences

for Sports and Management

Potsdam, Germany

Athanasios Chatzinikolaou,

Democritus University of Thrace,

Greece

${ }^{*}$ Correspondence: Billy Sperlich

billy.sperlich@uni-wuerzburg.de

Specialty section:

This article was submitted to

Exercise Physiology,

a section of the journal

Frontiers in Physiology

Received: 18 February 2020

Accepted: 22 June 2020

Published: 04 August 2020

Citation:

Becker M, Sperlich B, Zinner C and Achtzehn S (2020) Intra-Individual and Seasonal Variation of Selected

Biomarkers for Internal Load Monitoring in U-19 Soccer Players.

Front. Physiol. 11:838.

doi: 10.3389/fphys.2020.00838
The aim of this study was to investigate inter-day and -week as well as intra- and interindividual variation of selected biomarkers in high-performance youth soccer players to assist practitioners interpreting player's internal load to counteract underperformance and unwanted health risks. Eleven male youth soccer players were tested multiple times during two 3 -week periods at midpoint $\left(3-w k_{\text {mid }}\right)$ and at the end $\left(3-w k_{\text {end }}\right)$ of the first half of a German under-19 1. Bundesliga season. The levels of creatine kinase (CK), urea, and C-reactive protein (CRP) were measured during $3-w k_{\text {mid }}$ and $3-w k_{\text {end }}$ each Monday, Wednesday, and Friday. In 3-wk mid the CK median was 14\% higher (241 vs. $212 \mathrm{U} / \mathrm{L})$ compared to $3-\mathrm{wk}_{\text {end }}(P=0.26$, $\mathrm{ES}=0.16)$. Overall, the medians of $\mathrm{CK}$, urea $(P=0.59, \mathrm{ES}=0.08)$, and $\mathrm{CRP}(P=0.56, \mathrm{ES}=0.10)$ during $3-w k_{\text {mid }}$ did not differ to the values of $3-w k_{\text {end }}$. Daily coefficient of variations $(\mathrm{CVs})$ ranged from 22 to $71 \%(\mathrm{CK})$, 17 to $37 \%$ (urea), and 9 to $164 \%$ (CRP). Individual medians ranged from 101 to $350 \mathrm{U} / \mathrm{L}$ (CK), 23 to $50 \mathrm{mg} / \mathrm{dL}$ (urea), and 0.6 to $1.1 \mathrm{mg} / \mathrm{L}$ (CRP). High intra-individual variability was demonstrated by large intra-individual CVs (medians: CK 50\%, urea 18\%, and CRP 45\%). Our data show (i) large inter-day and inter-week variability of all biomarkers, depending on the external load and (ii) considerable inter- and intra-individual parameter variations. Creatine kinase concentrations could sensitively reflect soccer-specific loads during the season.

Keywords: biomarker variability, creatine kinase, soccer, youth soccer, internal load, monitoring, point of care testing

\section{INTRODUCTION}

Soccer players under the age of 19 (U-19) are exposed to frequent training sessions and matches, which are scheduled in one- or two-match weeks. It is well known that high match and frequent training session exposure in youth soccer players is associated with increased injury risks (Brink et al., 2010; Pfirrmann et al., 2016).

Monitoring internal and adjusting external load may ensure optimal training and match performances as well as prevent injuries over the course of an entire season. In this regard current 
expert opinion warrants objective and reliable methods (i) to adjust external load for optimal adaptation and prevention of overuse and (ii) to quantify each player's fatigue state (Nedelec et al., 2012). From a practical perspective, including that of coaches, monitoring of load designed to detect potential changes in health and performance should be valid, reliable and sensitive, as well as time-efficient, easily applicable, non-fatiguing and as non-invasive as possible (Starling and Lambert, 2018). Finally, dense biomarker monitoring is warranted in order to interpret time-courses of concentrations since most biomarkers are detectable up to several days (Ascensao et al., 2008).

Previous studies with professional soccer players revealed acutely increased creatine kinase (CK), urea, and C-reactive protein (CRP) concentrations induced by soccer-specific loads (de Hoyo et al., 2016; Mohr et al., 2016; Romagnoli et al., 2016) and by various other types of sport (Wiewelhove et al., 2015; Julian et al., 2017). Elevated levels of these markers occur in connection with different types of concentric and eccentric muscle contractions (Banfi et al., 2012). Especially eccentric muscle contractions induce muscle damage and soreness for up to $72 \mathrm{~h}$ after the match (Ispirlidis et al., 2008; Fatouros et al., 2010; Nedelec et al., 2012; Thorpe and Sunderland, 2012). Increase in soccer-related muscle damage is often associated with inflammatory response and accompanied by elevation of other blood markers including urea and CRP (Nedelec et al., 2012). With several matches per week and frequent training sessions the concentrations of CK, urea, and CRP might not return to baseline over several weeks.

Therefore, in-season monitoring of CK, urea, and CRP may assist estimating the internal load of muscles, metabolism, and unspecific inflammatory condition (Pepys and Hirschfield, 2003; Brancaccio et al., 2010). Advancements in point-of-care testing (POCT) allow rapid, frequent, and instant evaluation of numerous valid biomarkers for load management, including CK, urea, and CRP (Achtzehn et al., 2018) and dense monitoring may assist coaches in assessing youth player's load in connection with training and soccer matches (Kunz et al., 2019). Even though dense and frequent monitoring is recommended for load management (Wiewelhove et al., 2015), no study has investigated the intra-individual and seasonal kinetics of selected biomarkers in high-performance U-19 soccer players every second or third day for several weeks.

This exploratory study aimed to compare two selected time periods within a national $U-19$ soccer season to investigate (i) the inter- and intra-individual kinetics of selected biomarkers and (ii) the seasonal inter-day and inter-week variability of CK, urea, and CRP. From a practical perspective the study results should assist assessing high-performance youth soccer players' internal load to counteract underperformance and unwanted health risks.

\section{MATERIALS AND METHODS}

\section{Participants}

Eleven male youth soccer players of a German U-19 first league (1. Bundesliga) team were tested $(18 \pm 1 \mathrm{yrs} ; 180 \pm 10 \mathrm{~cm}$; $72 \pm 6 \mathrm{~kg}$ ) during two 3 -wk periods. Table 1 summarizes
TABLE 1 | Selected performance variables of each players at the beginning of the season.

\begin{tabular}{llccc}
\hline Player ID Position & $\begin{array}{c}\text { YoYo intermittent } \\
\text { recovery test } \\
\text { Level } \mathbf{2}(\mathbf{m})\end{array}$ & $\begin{array}{c}\text { Running speed at } \\
\mathbf{4} \text { mmol/L Blood } \\
\text { lactate during } \\
\text { incremental } \\
\text { testing (m/s) }\end{array}$ & $\begin{array}{c}\text { Time } \\
\text { 30m-Sprint (s) }\end{array}$ \\
\hline 1 & d mid & 1,120 & 3.85 & 4.34 \\
2 & d mid & 1,220 & 4.01 & n.d. \\
3 & for & 1,020 & 3.85 & 4.11 \\
4 & def & 1,380 & 3.77 & 4.28 \\
5 & o mid & 800 & 3.67 & 3.97 \\
6 & for & 1,220 & 3.92 & 3.99 \\
7 & def & 1,180 & 3.73 & 4.12 \\
8 & d mid & 1,300 & 3.9 & 4.34 \\
9 & mid & 1,260 & 3.84 & 4.14 \\
10 & mid & 1,260 & 3.46 & 4.06 \\
11 & o mid & n.d. & 4.21 & 4.00 \\
Team mean & $1,176 \pm 164$ & $3.83 \pm 0.19$ & $4.13(0.14)$ \\
\hline
\end{tabular}

def, defender; d mid, defensive midfielder; mid, midfielder; o mid, offensive midfielder; for, forward; n.d., not determined.

important performance variables of each player at the beginning of the season.

Two players were members of the U-19 national teams of Germany and Poland. We investigated only field players since physical requirements vary widely between field players and goalkeepers. All players were informed about all testing and signed an informed consent. This study was approved by the ethics committee of the German Sport University (Cologne, Germany) and was conducted according to the Declaration of Helsinki.

\section{Research Design}

All data were obtained on 18 testing days in two 3-wks periods, i.e., at midpoint $\left(3-\mathrm{wk}_{\mathrm{mid}}\right)$ and at the end of the first half of the season (3-wk $\mathrm{k}_{\text {end }}$ ) during a German U-19 first league season. A total of $3-\mathrm{wk}_{\text {mid }}$ took place between match 5 and $8,3-\mathrm{wk}_{\mathrm{end}}$ between match 10 and 14, which was at the end of the first half season (Figure 1). Due to the teams' scheduling of training sessions and camps as well as administrative difficulties it was not possible to start the investigation at the beginning of the season as initially intended.

Before and after each week of $3-w_{\mathrm{mid}}$ and $3-\mathrm{wk}_{\mathrm{end}}$, the participants played one U-19 first league match on either Saturday or Sunday (kickoff between 11.00 a.m. and 1.00 p.m.). Two first league matches were scheduled before the $3-w_{\text {end }}$ (rounds 10 and 11 were played on Thursday 6.30 p.m. and Sunday 1.00 p.m.).

Tables 2A,B summarize the main content of every training session including session duration and intensity, external load and the responses of CK, urea, and CRP. The intensity zones ( 1 = easy, 2 = moderate, and 3 = hard) were set according to the coach's subjective rating of intensity. External load was defined as the time spent in each intensity zone multiplied with the coach's subjective ranking (i.e., time in zone $1 \times 1$, time in zone $2 \times 2$, and time in zone $3 \times 3$ ). The players with more than $45-\mathrm{min}$ 


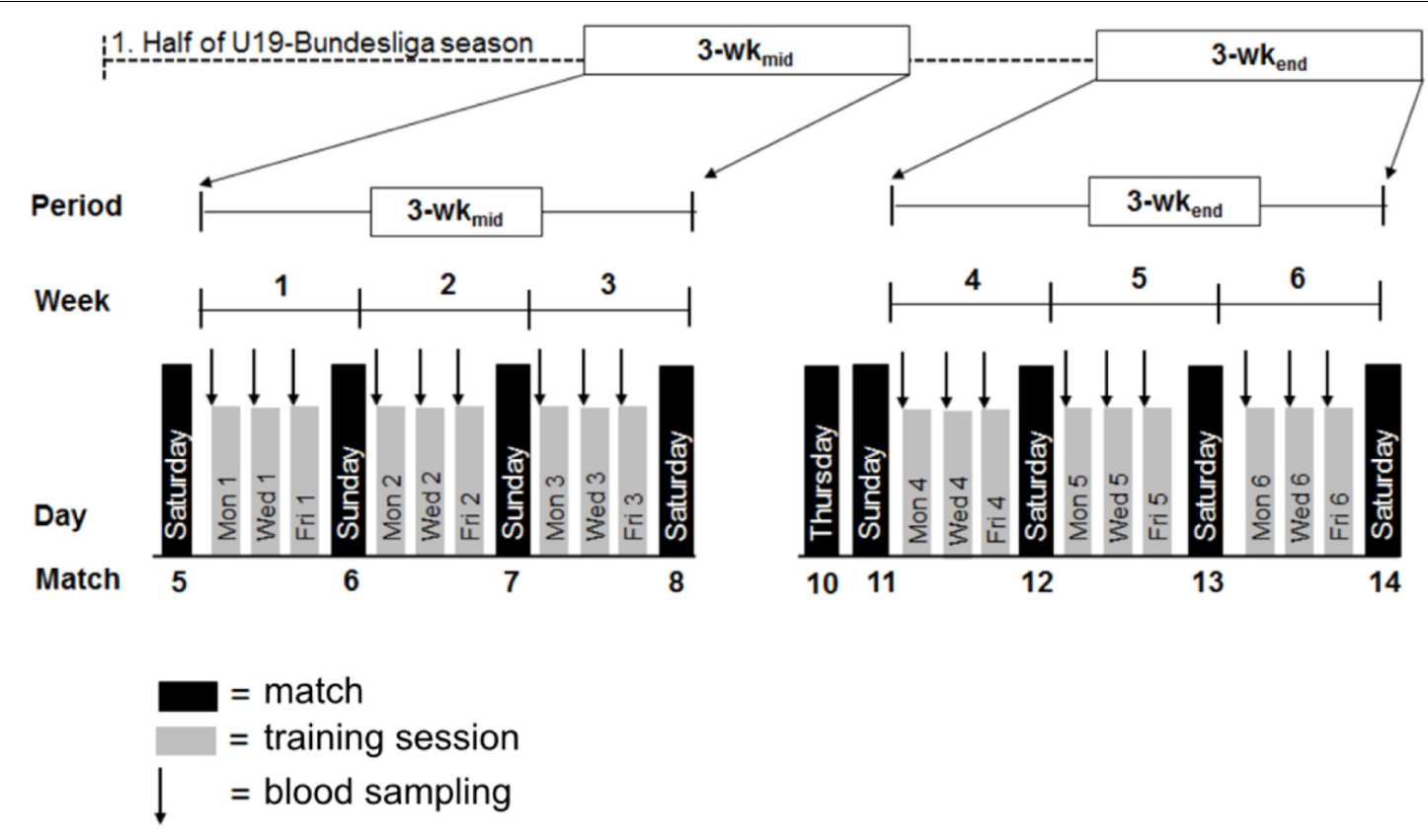

FIGURE 1 | Schematic illustration of the study design with all procedures. Black arrows indicate weekdays of blood sampling (on every Monday, Wednesday, and Friday).

match participation were defined as starters, players with less than 45-min match participation as substitutes.

Because of the observational nature of this study, data were analyzed retrospectively. Therefore, the present results had no immediate consequences for coaches and medical staff to adjust training load, medication or recovery strategies by coaches or the medical staff.

\section{Blood Sampling and Processing}

During $3-\mathrm{wk}_{\mathrm{mid}}$ and $3-\mathrm{wk}_{\mathrm{end}}$ on every Monday (Mon), Wednesday (Wed), and Friday (Fri) capillary blood was sampled from the participants' earlobe before the beginning of each training session and analyzed immediately after sampling. Training sessions commenced at 5.00 p.m on Mon, at 11.30 a.m. on Wed, and at 3.00 p.m. on Fri. Only on Wed1 (i.e., the first Wednesday for data collection) the training began at 5.30 p.m. On Wed6 (i.e., the 6th Wednesday for data collection) all players had one day off, so all testing was canceled by the coaches.

Creatine kinase and urea concentrations in each $32 \mu \mathrm{L}$ blood samples were analyzed employing Reflotron ${ }^{\circledR}$ Plus system (Roche Diagnostics, Mannheim, Germany). The measuring ranges were 24.4 to $1,700 \mathrm{U} / \mathrm{L}(\mathrm{CK})$ and 20.0 to $300.0 \mathrm{mg} / \mathrm{dL}$ (urea). The intra-assay coefficient of variation $(\mathrm{CV})$ (testretest reliability) for $\mathrm{CK}$ was $3.5 \%$ and for urea $\leq 3.0 \%$. The inter-assay CV (day-to-day reliability) for $\mathrm{CK}$ was $\leq 4.2 \%$ and for urea $\leq 3.5 \%$. QuikRead go $^{\circledR}$ hsCRP + Hb tests for a QuikRead go ${ }^{\circledR}$ photometer (Orion Diagnostica, Espoo, Finland) determined CRP concentration from $20 \mu \mathrm{L}$ capillary blood sample. During the last two weeks of the study QuikRead go ${ }^{\circledR}$ wrCRP $+\mathrm{Hb}$ tests were used, whereby only $10 \mu \mathrm{L}$ of blood were needed. Measuring ranges were 0.50 to $75.00 \mathrm{mg} / \mathrm{L}$ (hsCRP), and 0.50 to $300.00 \mathrm{mg} / \mathrm{L}$ (wrCRP), respectively. The intra-assay $\mathrm{CV}$ for hsCRP $\leq 5.9 \%$ and for wrCRP $\leq 4.9 \%$. The inter-assay CV for hsCRP $\leq 2.7 \%$ and for wrCRP $\leq 4.8 \%$.

\section{Statistical Analyses}

Data distribution with Kolmogorov-Smirnov and the ShapiroWilk test showed no normal distribution of CK $(P=0.001$ and $P<0.001$, respectively), CRP $(P<0.001$ and $P<0.001$, respectively), and urea $(P<0.001$ and $P<0.001$, respectively) concentrations. Therefore, all data are presented in box plots as medians, 25 to $75 \%$ percentiles as well as minimum and maximum values. Inter-day and inter-week variability are demonstrated by boxplots which represent the results from every testing day. Intra- and inter-individual variability are demonstrated by boxplots representing the results from every player during the observation period. The CV quantified the parameter variability and was defined as standard deviation divided by mean value multiplied by 100 . CV was determined for all biomarkers during the complete study process as well as for $3-w_{k} k_{\text {mid }}$ and $3-w_{\text {end }}$ and for all testing days. $\mathrm{CV}$ was calculated from the individual parameter responses in the study process to quantify intra-individual variability. The differences between $3-w_{\mathrm{mid}}$ and $3-\mathrm{wk}_{\text {end }}$ were assessed employing Wilcoxon comparison. The effect size (ES) measurement for non-parametric tests $(r=\mathrm{Z} / \sqrt{ } \mathrm{N})$ (Rosenthal, 1994) were calculated between $3-\mathrm{wk}_{\mathrm{mid}}$ and 3$\mathrm{wk}_{\mathrm{end}}$. The level of significance was $P \leq 0.05$. The analyses were carried out with SPSS Statistics 24 (IBM, Chicago, IL, United States) and Excel 2010 (Microsoft Corp., Redmond, WA, United States), respectively. 
TABLE 2 | Day of testing, session duration, main content, intensity, external load, and the responses of creatine kinase, urea, and C-reactive protein (CRP).

\begin{tabular}{|c|c|c|c|c|c|c|}
\hline (A) & & & & Analysis of $3-w_{k_{\text {mid }}}$ & & \\
\hline Day & $\begin{array}{c}\text { Session } \\
\text { duration }(\mathrm{min})\end{array}$ & $\begin{array}{l}\text { Intensity } \\
\text { 1/2/3 (min) }\end{array}$ & $\begin{array}{l}\text { External } \\
\text { load (a.u.) }\end{array}$ & Creatine kinase $(\mathrm{U} / \mathrm{L})$ & Urea (mg/dL) & CRP (mg/L) \\
\hline
\end{tabular}

$(n) /$ substitutes (n)

(n)/substitutes ( $n$ )

(n)/substitutes (n)

\begin{tabular}{|c|c|c|c|c|c|c|c|c|c|c|c|c|c|}
\hline Satpre & $54+35$ & Match + warm up and cool-down & $10 / 25 / 54$ & 222 & & & & & & & & & \\
\hline Sun $_{\text {pre }}$ & 0 & No training & 0/0/0 & 0 & & & & & & & & & \\
\hline Mon1 & 85 & Strength, recovery & $40 / 30 / 15$ & 145 & $\begin{array}{r}229(11) 364 \\
(7) / 162(4)\end{array}$ & $76 / 645$ & 59 & $\begin{array}{l}30(11) 30 \\
(7) / 30(4)\end{array}$ & $20 / 63$ & 37 & $\begin{array}{r}0.7(10) 1.0 \\
(6) / 0.7(4)\end{array}$ & $0.5 / 3.1$ & 76 \\
\hline Tue1 & 80 & Tactical drills, training match & $30 / 30 / 20$ & 150 & & & & & & & & & \\
\hline Wed1 & 95 & strength, speed, tactical drills & $30 / 15 / 50$ & 210 & $\begin{array}{c}264(8) 252 \\
(6) / 273(2)\end{array}$ & $168 / 465$ & 32 & $\begin{array}{l}47 \text { (8) } 46 \\
(6) / 47 \text { (2) }\end{array}$ & $26 / 55$ & 24 & $\begin{array}{l}0.7(7) 0.7 \\
(5) / 0.8(2)\end{array}$ & $0.5 / 1.3$ & 32 \\
\hline Thu1 & 0 & No training & 0/0/0 & 0 & & & & & & & & & \\
\hline Fri1 & 60 & Tactical drills, training match & $15 / 20 / 25$ & 130 & $\begin{array}{c}166(9) 174 \\
(6) / 164(3)\end{array}$ & $74 / 323$ & 41 & $\begin{array}{l}33(9) 30 \\
(6) / 40(3)\end{array}$ & $22 / 58$ & 34 & $\begin{array}{l}0.7(6) 0.7 \\
\quad(4) / 0.7(2)\end{array}$ & $0.5 / 1.0$ & 23 \\
\hline Sat1 & 55 & Tactical drills, speed, training match & $15 / 25 / 15$ & 110 & & & & & & & & & \\
\hline Sun1 & $45+35$ & Match + warm up and cool-down & $10 / 25 / 45$ & 195 & & & & & & & & & \\
\hline Mon2 & 85 & Tactical drills, recovery & $50 / 30 / 5$ & 125 & $\begin{array}{r}337(10) 381 \\
(6) / 233(4)\end{array}$ & $77 / 511$ & 44 & $\begin{array}{r}36(10) 36 \\
(6) / 38(4)\end{array}$ & 20/65 & 36 & $\begin{array}{l}1.2(8) 1.5 \\
(6) / 0.5(2)\end{array}$ & $0.5 / 4.5$ & 83 \\
\hline \multirow[t]{2}{*}{ Tue2 } & 30 & Strength & $15 / 5 / 10$ & 55 & & & & & & & & & \\
\hline & 75 & Tactical drills & $30 / 30 / 15$ & 135 & & & & & & & & & \\
\hline \multirow[t]{2}{*}{ Wed2 } & 45 & Strength, speed & $5 / 5 / 35$ & 120 & $\begin{array}{r}289(9) 276 \\
(5) / 374(4)\end{array}$ & $149 / 544$ & 36 & $\begin{array}{l}34(9) 27 \\
(5) / 40(4)\end{array}$ & $20 / 50$ & 34 & $\begin{array}{l}0.9(6) 0.6 \\
(3) / 1.1 \text { (3) }\end{array}$ & $0.6 / 2.2$ & 54 \\
\hline & 55 & Tactical drills, recovery & $30 / 10 / 15$ & 95 & & & & & & & & & \\
\hline Thu2 & 0 & No training & 0/0/0 & 0 & & & & & & & & & \\
\hline Fri2 & 60 & Tactical drills, training match & $15 / 20 / 25$ & 130 & $\begin{array}{c}171(8) 171 \\
(4) / 196(4)\end{array}$ & $101 / 366$ & 39 & $\begin{array}{l}34(8) 25 \\
(4) / 40(4)\end{array}$ & $20 / 46$ & 30 & $\begin{array}{c}0.6(8) 0.6 \\
(4) / 0.6(4)\end{array}$ & $0.5 / 1.0$ & 23 \\
\hline Sat2 & 55 & Tactical drills, speed, training match & 15/25/15 & 110 & & & & & & & & & \\
\hline Sun2 & $44+35$ & Match + warm up and cool-down & $10 / 25 / 44$ & 192 & & & & & & & & & \\
\hline Mon3 & 55 & Recovery & $40 / 15 / 0$ & 70 & $\begin{array}{r}299(9) 310 \\
(5) / 253(4)\end{array}$ & $147 / 665$ & 44 & $\begin{array}{l}42(9) 43 \\
(5) / 39(4)\end{array}$ & $22 / 71$ & 34 & $\begin{array}{l}0.8 \text { (8) } 0.9 \\
(4) / 0.7 \text { (4) }\end{array}$ & $0.5 / 1.8$ & 45 \\
\hline \multirow[t]{2}{*}{ Tue3 } & 30 & Strength & $15 / 5 / 10$ & 55 & & & & & & & & & \\
\hline & 75 & Tactical drills & $30 / 30 / 15$ & 135 & & & & & & & & & \\
\hline Wed3 & 50 & Strength, speed & $5 / 0 / 45$ & 140 & $\begin{array}{r}368(6) 329 \\
(3) / 406(3)\end{array}$ & $227 / 575$ & 31 & $\begin{array}{l}32(6) 42 \\
(3) / 27 \text { (3) }\end{array}$ & $27 / 50$ & 25 & $\begin{array}{l}0.7(5) 0.7 \\
\quad(3) / 1.9(2)\end{array}$ & $0.6 / 2.3$ & 57 \\
\hline Thu3 & 60 & Tactical drills, training match & $15 / 20 / 25$ & 130 & & & & & & & & & \\
\hline Fri3 & 55 & Tactical drills, speed, training match & $15 / 25 / 15$ & 110 & $\begin{array}{r}219(9) 219 \\
(5) / 270(4)\end{array}$ & $177 / 569$ & 42 & $\begin{array}{l}33(9) 38 \\
(5) / 32(4)\end{array}$ & $20 / 50$ & 28 & $\begin{array}{l}0.9(7) 0.6 \\
(3) / 1.2(4)\end{array}$ & $0.6 / 1.3$ & 31 \\
\hline Sat3 & $52+35$ & Match + warm up and cool-down & $10 / 25 / 52$ & 216 & & & & & & & & & \\
\hline Sun3 & 0 & No training & 0/0/0 & 0 & & & & & & & & & \\
\hline
\end{tabular}


TABLE 2 | Continued

(B)

Analysis of 3-wk

Day Session Main content

duration (min)

Intensity External Creatine kinase (U/L)

Urea $(\mathrm{mg} / \mathrm{dL})$

CRP (mg/L)

1/2/3 (min) load (a.u.)

Median (n)/starter Min/Max CV (\%) Median (n)/starter M

$(n) /$ substitutes (n)

Median (n)/starter Min/Max CV (\%)

(n)/substitutes ( $n$

\begin{tabular}{|c|c|c|c|c|c|c|c|c|c|c|c|c|c|}
\hline Thupre & $54+35$ & Match + warm up and cool-down & $10 / 25 / 54$ & 222 & & & & & & & & & \\
\hline Fripre & 55 & Tactical drills, recovery & $45 / 10 / 0$ & 65 & & & & & & & & & \\
\hline Satpre & 55 & Tactical drills, speed, training match & $15 / 25 / 15$ & 110 & & & & & & & & & \\
\hline Sun pre & $39+35$ & Match + warm up and cool-down & $10 / 25 / 39$ & 177 & & & & & & & & & \\
\hline Mon4 & 50 & Tactical drills, recovery & $40 / 10 / 0$ & 60 & $\begin{array}{r}204(10) 576 \\
(4) / 168(6)\end{array}$ & $97 / 791$ & 71 & $\begin{array}{l}41(10) 37 \\
(4) / 43(6)\end{array}$ & $27 / 59$ & 20 & $\begin{array}{c}1(10) 1.1 \\
(4) / 0.9(6)\end{array}$ & $0.6 / 1.8$ & 40 \\
\hline Tue4 & 0 & No training & 0/0/0 & 0 & & & & & & & & & \\
\hline \multirow[t]{2}{*}{ Wed4 } & 65 & Strength, speed, tactical drills & $15 / 15 / 35$ & 150 & $\begin{array}{r}135(8) 180 \\
(3) / 115(5)\end{array}$ & $55 / 213$ & 40 & $\begin{array}{l}31(8) 23 \\
(3) / 31(5)\end{array}$ & $20 / 43$ & 24 & $\begin{array}{l}0.9(3) 0.9 \\
(2) / 1.0(1)\end{array}$ & $0.8 / 1.0$ & 9 \\
\hline & 70 & Tactical drills, training match & $30 / 15 / 25$ & 135 & & & & & & & & & \\
\hline Thu4 & 70 & Tactical drills, training match & $70 / 20 / 20$ & 170 & & & & & & & & & \\
\hline Fri4 & 55 & Tactical drills, speed, training match & $15 / 25 / 15$ & 110 & $\begin{array}{r}323(10) 376 \\
(4) / 236(6)\end{array}$ & $212 / 555$ & 29 & $\begin{array}{l}40(10) \\
30(4) / 46(6)\end{array}$ & $21 / 50$ & 26 & $-(0)$ & - & - \\
\hline Sat4 & $47+35$ & Match + warm up and cool-down & $10 / 25 / 47$ & 201 & & & & & & & & & \\
\hline Sun4 & 25 & Recovery & $25 / 0 / 0$ & 25 & & & & & & & & & \\
\hline Mon5 & 70 & Strength, tactical drills, recovery & $45 / 15 / 10$ & 105 & $\begin{array}{r}152(9) 193 \\
(4) / 133(5)\end{array}$ & $54 / 307$ & 46 & $\begin{array}{l}38(9) 38 \\
(4) / 40(5)\end{array}$ & $23 / 57$ & 26 & $\begin{array}{l}0.6(9) 0.5 \\
(4) / 1.1(5)\end{array}$ & $0.5 / 3.2$ & 79 \\
\hline Tue5 & 90 & Tactical drills, training match & $30 / 25 / 35$ & 185 & & & & & & & & & \\
\hline Wed5 & 60 & Strength, speed & $15 / 5 / 40$ & 145 & $\begin{array}{r}274(7) 293 \\
(3) / 233(4)\end{array}$ & $175 / 464$ & 34 & $\begin{array}{c}36(7) 42 \\
(3) / 33(4)\end{array}$ & $26 / 50$ & 21 & $\begin{array}{l}0.7(7) 0.7 \\
(3) / 1.1(4)\end{array}$ & $0.5 / 11.0$ & 157 \\
\hline Thu5 & 55 & Tactical drills, training match & $15 / 5 / 35$ & 130 & & & & & & & & & \\
\hline Fri5 & 55 & Tactical drills, speed, training match & $15 / 25 / 15$ & 110 & $\begin{array}{r}306(7) 281 \\
(3) / 317(4)\end{array}$ & $148 / 352$ & 22 & $\begin{array}{l}43(7) 44 \\
(3) / 37(4)\end{array}$ & $30 / 54$ & 22 & $\begin{array}{c}0.5(7) 0.5 \\
(3) / 0.8(4)\end{array}$ & $0.5 / 9.1$ & 164 \\
\hline Sat5 & $44+35$ & Match + warm up and cool-down & $10 / 25 / 44$ & 192 & & & & & & & & & \\
\hline Sun5 & 0 & No training & 0/0/0 & 0 & & & & & & & & & \\
\hline Mon6 & 60 & Strength, tactical drills, recovery & $45 / 15 / 0$ & 75 & $\begin{array}{r}165(8) 231 \\
(5) / 117 \text { (3) }\end{array}$ & $66 / 296$ & 43 & $\begin{array}{c}33(8) 34 \\
(5) / 29(3)\end{array}$ & $23 / 60$ & 33 & $\begin{array}{l}0.5(8) 0.5 \\
(5) / 0.5(3)\end{array}$ & $0.5 / 3.3$ & 94 \\
\hline \multirow[t]{2}{*}{ Tue6 } & 65 & Strength, speed, tactical drills & $15 / 15 / 35$ & 150 & & & & & & & & & \\
\hline & 75 & Tactical drills, training match & $25 / 20 / 30$ & 155 & & & & & & & & & \\
\hline Wed6 & 0 & No training & 0/0/0 & 0 & $-(0)$ & $-1-$ & - & $-(0)$ & $-/-$ & - & $-(0)$ & $-1-$ & - \\
\hline Thu6 & 0 & No training & 0/0/0 & 0 & & & & & & & & & \\
\hline Fri6 & 45 & Tactical drills, speed, training match & $15 / 15 / 15$ & 90 & $\begin{array}{r}111(8) 104 \\
(5) / 118(3)\end{array}$ & $56 / 230$ & 40 & $\begin{array}{l}35(8) 35 \\
(5) / 32(3)\end{array}$ & $21 / 40$ & 17 & $\begin{array}{l}0.6(8) 0.5 \\
(5) / 0.6(3)\end{array}$ & $0.5 / 2.1$ & 66 \\
\hline Sat6 & $48+35$ & Match + warm up and cool-down & $10 / 25 / 48$ & 204 & & & & & & & & & \\
\hline Sun6 & 0 & Beginning of winter break & 0/0/0 & 0 & & & & & & & & & \\
\hline
\end{tabular}




\section{RESULTS}

\section{Biomarker Responses During 3-wk $\mathbf{m i d}_{\text {m }}$ and 3-wk $\mathbf{k}_{\text {end }}$}

Figure 2 illustrates the median variation of creatine kinase, urea and CRP and session duration during both observation periods (3-wk $\mathrm{wid}_{\mathrm{mid}}$ and $\left.3-\mathrm{wk}_{\mathrm{end}}\right)$.

Table 3 shows the median as well as minimum and maximum values and CVs of CK, urea, and CRP during $3-\mathrm{wk}_{\mathrm{mid}}$ and 3 $\mathrm{wk}_{\mathrm{end}}$. Overall, the medians of CK $(P=0.26, \mathrm{ES}=0.16)$, urea $(P=0.59, \mathrm{ES}=0.08)$, and $\mathrm{CRP}(P=0.56, \mathrm{ES}=0.10)$ in $3-\mathrm{wk}_{\mathrm{mid}}$ did not differ compared to the values of $3-\mathrm{wk}_{\mathrm{end}}$.

The external load did not differ between $3-w^{\text {mid }}$ and $3-w_{\text {end }}$ $(P=0.80 ; \mathrm{ES}=0.06)$.

During both observation periods the biomarkers ranged from 47 to $791 \mathrm{U} / \mathrm{L}$ (CK), 20 to $71 \mathrm{mg} / \mathrm{dL}$ (urea), and 0.5 to $11.0 \mathrm{mg} / \mathrm{L}$ (CRP), respectively. CVs ranged from 33 (urea, $3-\mathrm{wk}_{\mathrm{mid}}$ ) to $147 \%$ (CRP, 3-wk end $_{\text {). }}$

Results from Fri6 were excluded in Tables 2A,B because all players had two successive days off on the previous days and consequently external load was different before Fri6 compared to the other testing days. Therefore, $146 \mathrm{CK}$ and urea as well as 116 CRP tests were analyzed in Tables 2A,B.

\section{Seasonal Inter-Day and Inter-Week Variability and Correlation of CK, Urea, and CRP}

Figure 3 and Tables 2A,B summarize the inter-day (e.g., Mon1 vs. Wed1 vs. Fri1) and inter-week (e.g., Mon1 vs. Mon2 vs. Mon3) variability of CK, urea, and CRP. In $3-w_{\text {mid }}$ CK medians were higher every Mon and Wed compared to the values on Fri (e.g.,
Mon1: 229 U/L (+ 38\%), Wed1: 264 U/L (+ 59\%), and Fri1: $166 \mathrm{U} / \mathrm{L})$. CRP medians in week 1 and 2 were also higher on Mon and Wed compared to Fri (e.g., Mon2: $1.2 \mathrm{mg} / \mathrm{L}(+100 \%)$, Wed2: $0.9 \mathrm{mg} / \mathrm{L}(+42 \%)$, and Fri2: $0.6 \mathrm{mg} / \mathrm{L})$. In $3-\mathrm{wk}_{\mathrm{mid}}$ daily mean $\mathrm{CK}$ and $\mathrm{CRP}$ values showed very large correlation $(r=0.87 ; P=0.001, n=10)$. In $3-\mathrm{wk}_{\mathrm{end}}$ daily mean $\mathrm{CK}$ and CRP values showed large correlation but not significant $(r=0.64$; $P=0.119, n=7)$.

In 3 -wk $_{\text {end }}$ urea medians on Fri4 $(41 \mathrm{mg} / \mathrm{dL},+31 \%)$ and Fri5 $(43 \mathrm{mg} / \mathrm{dL},+18 \%)$ were higher than on Wed4 $(31 \mathrm{mg} / \mathrm{dL})$ and Wed5 (36 mg/dL), respectively. Daily CVs ranged from 22\% (Fri5) to 71\% (Mon4) for CK, from 17\% (Fri6) to 37\% (Mon1) for urea and from 9 (Wed4) to 164\% (Fri5) for CRP concentrations.

One day after the matches (Mon2 and Mon3) median CK values (337 and $299 \mathrm{U} / \mathrm{L}$ ) were about 70\% higher than 2 days postmatch (Mon1, Mon4, Mon5, and Mon6) with CK medians ranging from 152 to $229 \mathrm{U} / \mathrm{L}$.

One day after match day median CRP values (1.2 and $0.8 \mathrm{mg} / \mathrm{L}$ ) were about $43 \%$ higher than after 2 days (range from 0.5 to $1.0 \mathrm{mg} / \mathrm{L}$ ), while median urea values were nearly unchanged between one ( 36 and $34 \mathrm{mg} / \mathrm{dL}$ ) and 2 days (range from 30 to $41 \mathrm{mg} / \mathrm{dL}$ ) postmatch.

\section{Inter- and Intra-Individual Variability of CK, Urea, and CRP}

The individual kinetics in Figure 4 and the box plots in Figure 5 illustrate the inter- and intra-individual variability of all biomarkers. Individual median values for $\mathrm{CK}$ responses ranged from 101 (player 10) to $350 \mathrm{U} / \mathrm{L}$ (player 1), for urea responses from 23 (player 5) to $50 \mathrm{mg} / \mathrm{dL}$ (player 11) and for CRP responses from 0.6 (player 1,6 , and 7 ) to $1.1 \mathrm{mg} / \mathrm{L}$ (player 8 and 10).
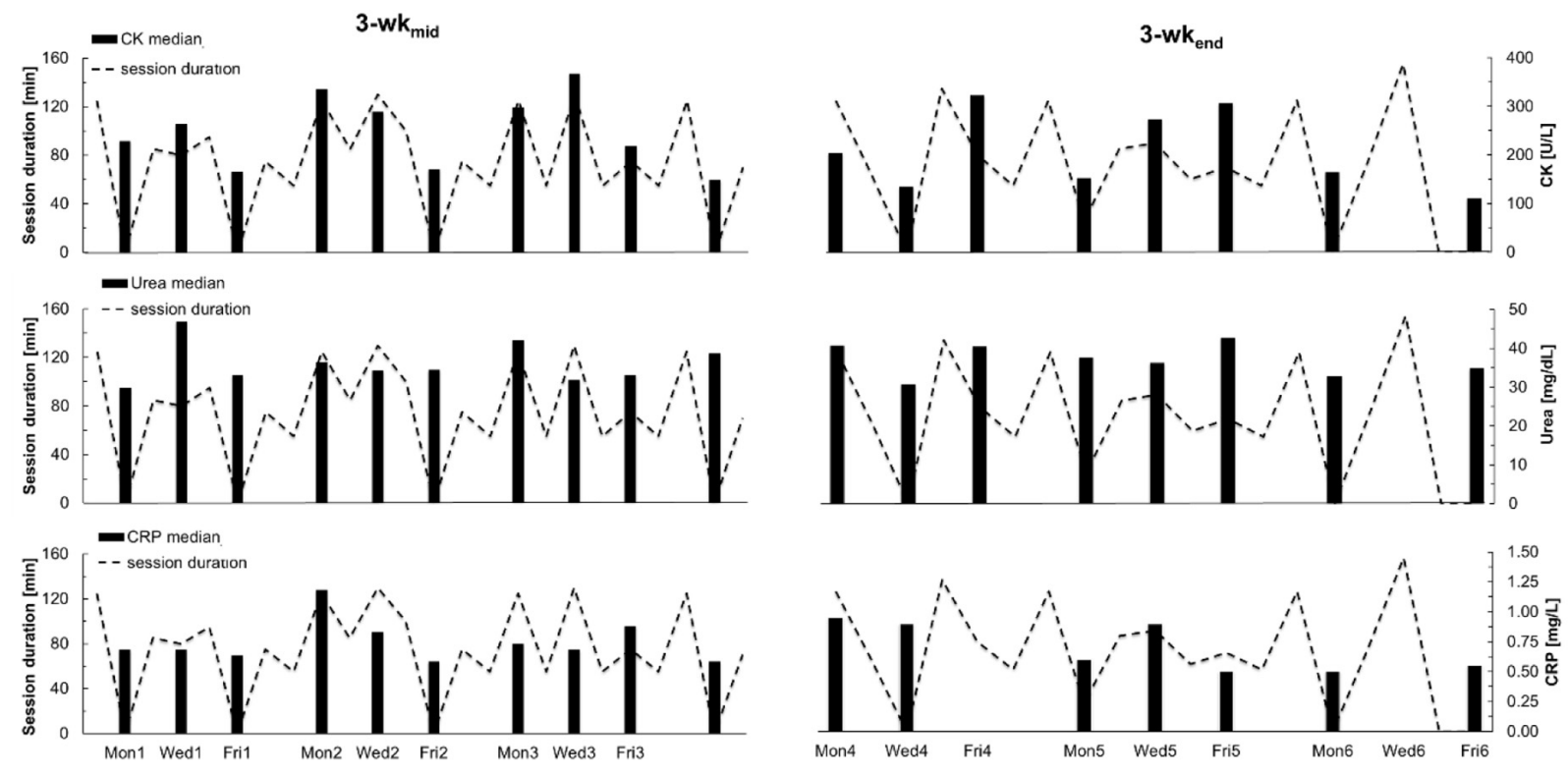

FIGURE 2 | Median variation of creatine kinase, urea and C-reactive protein and session duration (dotted lines) during both observation periods (3-wk mid and 3-wk end $_{\text {). }}$. 
TABLE 3 | Number of samples, median, minimum, and maximum as well as coefficients of variation of creatine kinase, urea, and C-reactive protein in both observation periods (3-wk mid and $\left.3-w k_{\text {end }}\right)$.

\begin{tabular}{|c|c|c|c|c|c|c|}
\hline & \multicolumn{2}{|c|}{ Creatine kinase (U/L) } & \multicolumn{2}{|c|}{ Urea (mg/dL) } & \multicolumn{2}{|c|}{ CRP (mg/L) } \\
\hline & $3-w k_{\text {mid }}$ & 3-wk end & 3-wk $k_{\text {mid }}$ & $3-w k_{\text {end }}$ & $3-w k_{\text {mid }}$ & 3-wkend \\
\hline Number of samples $(n)$ & 87 & 59 & 87 & 59 & 72 & 44 \\
\hline Median & 241 & 212 & 36 & 36 & 0.7 & 0.8 \\
\hline Minimum/maximum & $47 / 665$ & $54 / 791$ & $20 / 71$ & $20 / 60$ & $0.5 / 4.5$ & $0.5 / 11$ \\
\hline Coefficients of variation (\%) & 50 & 58 & 33 & 26 & 68 & 147 \\
\hline
\end{tabular}

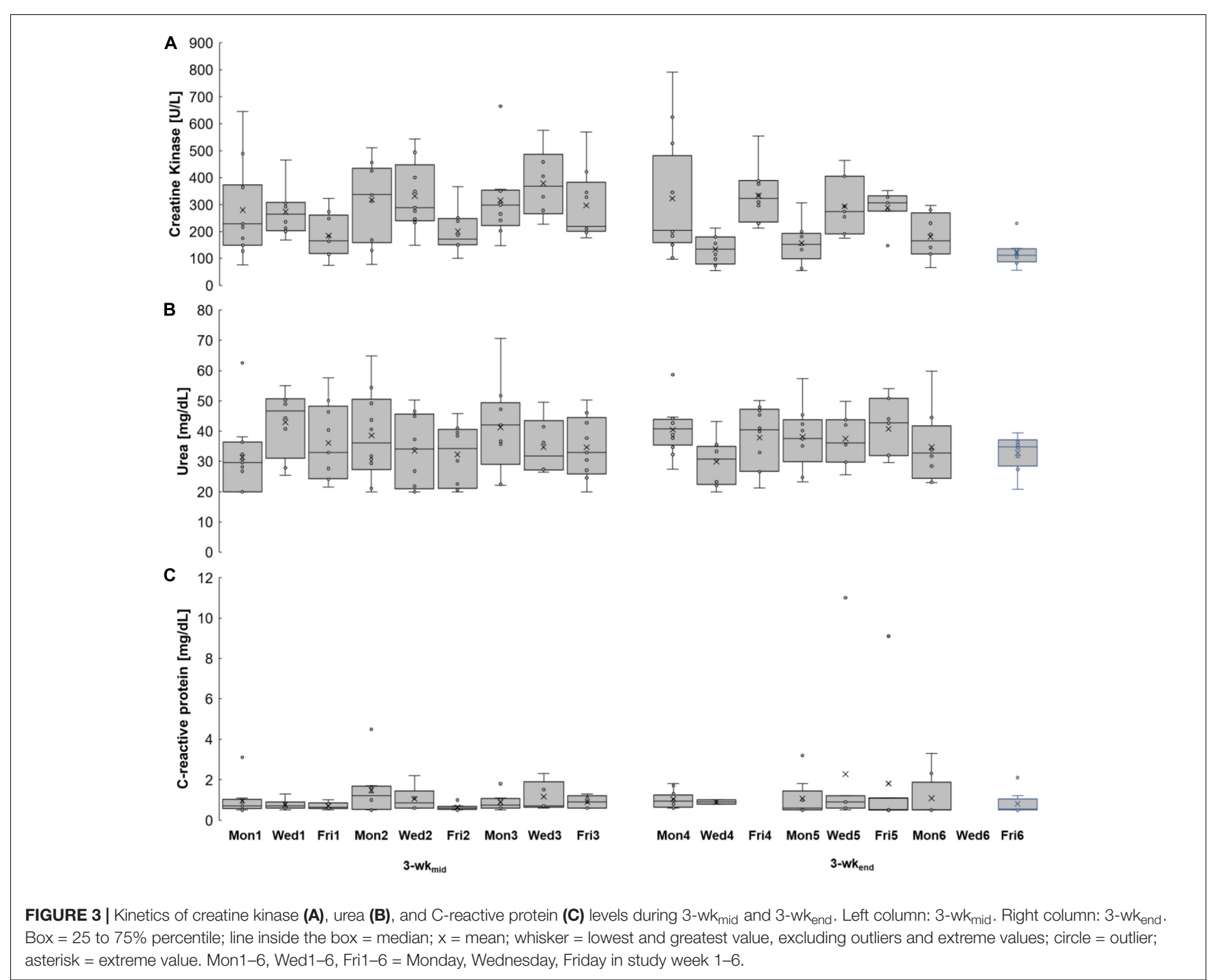

Individual CVs in Table 4 show a high inter-individual variation (CK: 33-64\%, urea: 14-22\%, and CRP: 15-136\%). High intra-individual variability is underlined by the broad range of each player's values [e.g., player 5 (CK): 98-665 U/L, player 9 (urea): $28-55 \mathrm{mg} / \mathrm{dL}$, player 10 (CRP): $0.5-11.0 \mathrm{mg} / \mathrm{L}$ ], validated by the team's median CV listed in Table 3 (CK: 50\%, urea: $18 \%$, and CRP: $45 \%$ ).

To illustrate inter- and intra-individual variability, only players with at least 11 analyzed blood tests were included.

\section{DISCUSSION}

The aim of the present study was to compare the results of two selected time periods within a soccer season, to investigate the inter-day and inter-week variability of selected biomarkers (CK, urea, and CRP) and to investigate the inter- and intra-individual kinetics of each variable. The main findings of this study were: (i) large inter-day and inter-week variability of all biomarkers and (ii) considerable inter- and intra-individual parameter variations. 

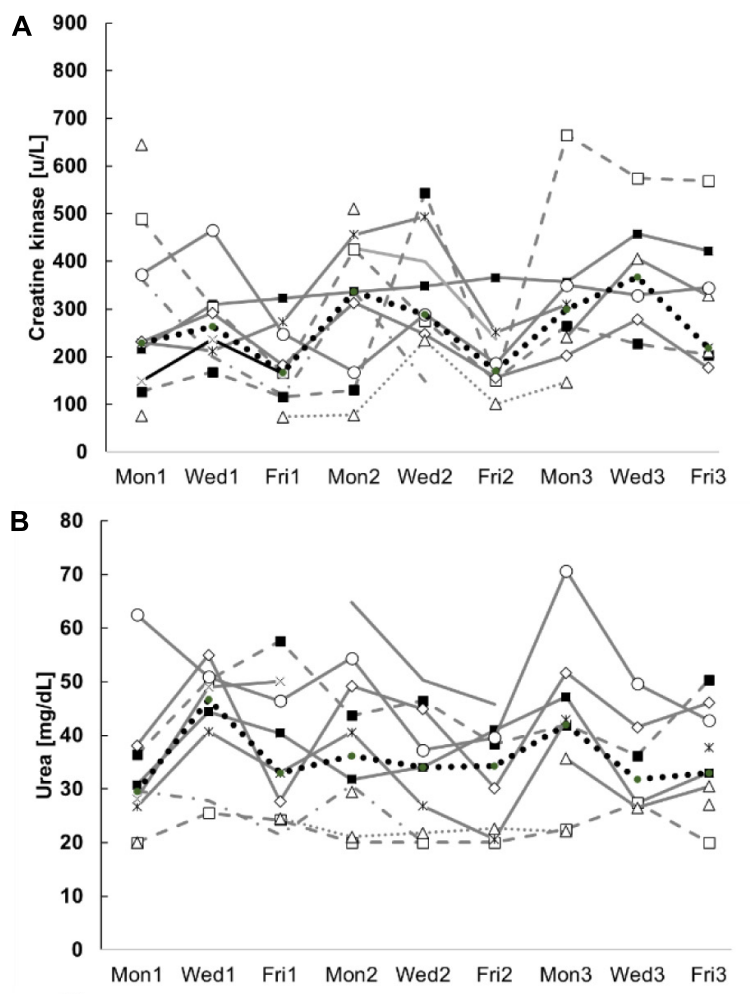

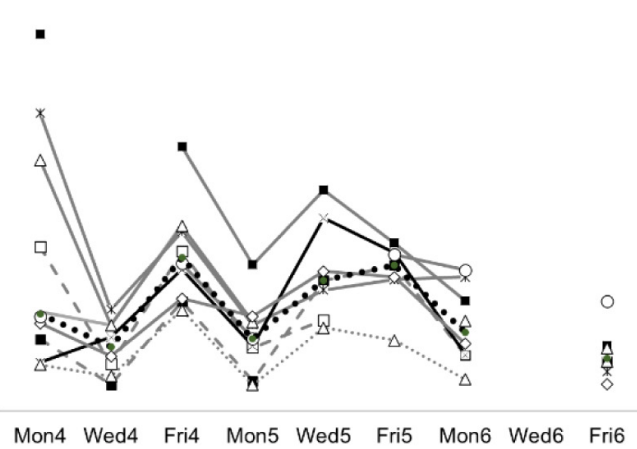

Mon4 Wed4 Fri4 Mon5 Wed5 Fri5 Mon6 Wed6 Fri6

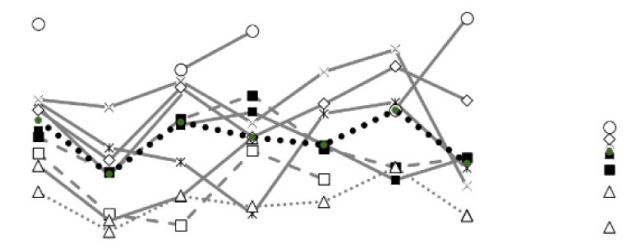

Mon4 Wed4 Fri4 Mon5 Wed5 Fri5 Mon6 Wed6 Fri6
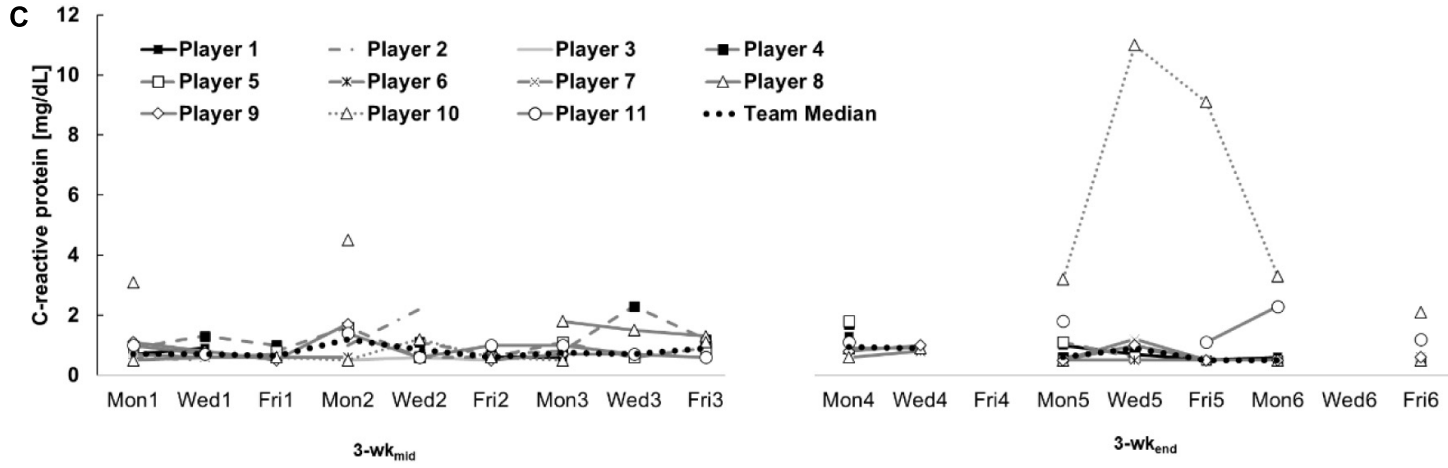

FIGURE 4 | Intra-individual creatine kinase (A), urea (B), and C-reactive protein (C) kinetics of eleven youth soccer players and the team's median during two investigation periods (3-wk mid and 3-wkend). Mon1 - Fri3 = 3-wk mid, Mon4 - Fri6 = 3-wkend.

\section{Inter-Day Variability of CK, Urea, and CRP}

Here we measured large inter-day variability of CK, urea, and CRP concentrations in youth players during two competition 3 -wk periods. Based on the large variability we conclude that testing of CK, urea, and CRP should be performed as frequently as possible to (i) understand the kinetics of each variable during a season and (ii) generate meaningful consequences for training and match tactics. For example, one blood test per week may assess the current status of CK, urea, and CRP, but single sampling prevents to judge whether the concentrations are increasing, peaking or decreasing. Therefore, when applying single measurements, e.g., one test each week, the potential for data interpretation - and consequently for practical consequences - is severely limited (as shown by the inter-day variation in Figure 5). Therefore, biomarker analyses should be implemented as a monitoring tool for trend diagnosis to assess the kinetics, and not only as status diagnosis. Sperlich et al. (2016) conducted day-to-day CK and urea tests during a 3-wk altitude training camp of national distance runners, while others (Hartmann and Mester, 2000) conducted dense urea monitoring in a single case study (type of sport is unknown) for approximately 4 weeks. Both studies also revealed large inter-day and intra- and inter-individual variability.

By viewing the CK-kinetics during the testing weeks one, two and three, it seems the coach's load programming was mirrored by CK since (as shown in Tables 2A,B) in each of these weeks the most intense training loads took place during the Tuesday and 


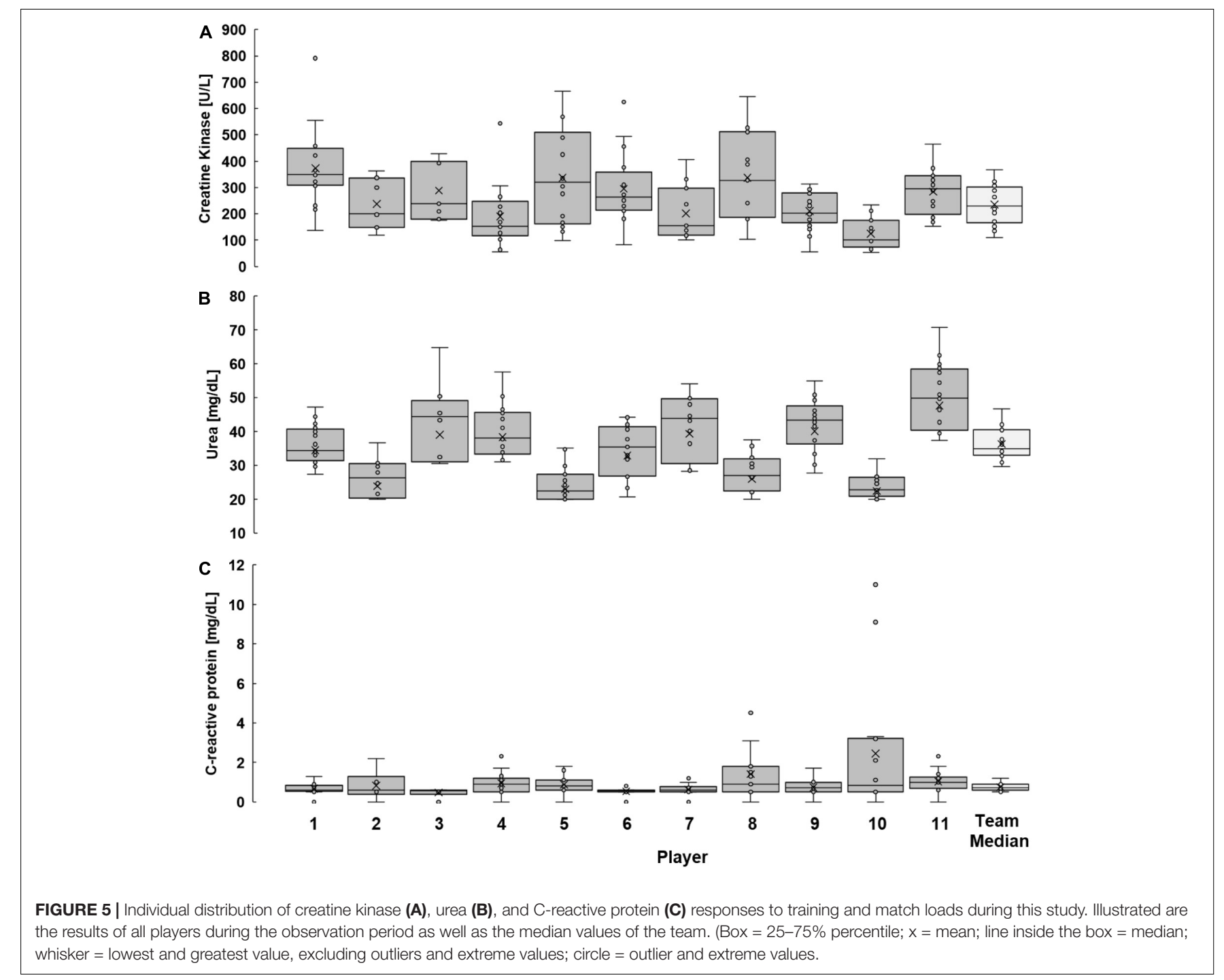

TABLE 4 | Creatine kinase, urea, and C-reactive protein responses of each player.

\begin{tabular}{|c|c|c|c|c|c|c|c|c|c|c|c|c|}
\hline \multirow[b]{2}{*}{ Player ID } & \multicolumn{4}{|c|}{ Creatine kinase (U/L) } & \multicolumn{4}{|c|}{ Urea (mg/dL) } & \multicolumn{4}{|c|}{ C-reactive protein (mg/L) } \\
\hline & $\begin{array}{l}\text { Number of } \\
\text { samples }\end{array}$ & Median & Min/Max & CV (\%) & (n) & Median & Min/Max & CV (\%) & $(n)$ & Median & Min/Max & CV (\%) \\
\hline 1 (d mid) & 16 & 350 & $137 / 791$ & 40 & 16 & 35 & $27 / 47$ & 15 & 11 & 0.6 & $0.5 / 1.3$ & 36 \\
\hline 2 (d mid) & 7 & 200 & $119 / 364$ & 36 & 7 & 28 & $20 / 37$ & 23 & 5 & 0.6 & $0.2 / 2.2$ & 80 \\
\hline 3 (for) & 7 & 238 & $175 / 428$ & 38 & 7 & 45 & $31 / 65$ & 25 & 5 & 0.6 & $0.5 / 0.6$ & 10 \\
\hline 4 (def) & 17 & 153 & $55 / 544$ & 63 & 17 & 38 & $31 / 58$ & 19 & 14 & 0.9 & $0.5 / 2.3$ & 53 \\
\hline 5 (o mid) & 14 & 320 & $98 / 665$ & 55 & 14 & 23 & $20 / 35$ & 22 & 10 & 0.9 & $0.6 / 1.8$ & 45 \\
\hline 6 (for) & 16 & 264 & $83 / 625$ & 46 & 16 & 36 & $21 / 44$ & 21 & 13 & 0.6 & $0.5 / 0.8$ & 15 \\
\hline 7 (def) & 11 & 155 & $102 / 405$ & 52 & 11 & 45 & $28 / 54$ & 18 & 9 & 0.6 & $0.5 / 1.2$ & 37 \\
\hline 8 (d mid) & 11 & 328 & $104 / 645$ & 44 & 11 & 27 & $20 / 38$ & 18 & 10 & 1.1 & $0.5 / 4.5$ & 81 \\
\hline 9 (mid) & 17 & 203 & $56 / 313$ & 34 & 17 & 44 & $28 / 55$ & 18 & 14 & 0.7 & $0.5 / 1.7$ & 43 \\
\hline 10 (mid) & 15 & 101 & $54 / 234$ & 48 & 15 & 23 & $20 / 32$ & 14 & 13 & 1.1 & $0.5 / 11.0$ & 134 \\
\hline 11 (o mid) & 15 & 296 & $152 / 465$ & 30 & 15 & 50 & $37 / 71$ & 19 & 13 & 1.0 & $0.6 / 2.3$ & 46 \\
\hline Team median & 15 & 238 & $102 / 465$ & 44 & 15 & 36 & $27 / 47$ & 19 & 11 & 0.7 & $0.5 / 1.8$ & 45 \\
\hline
\end{tabular}

def, defender; a mid, defensive midfielder; mid, midfielder; o mid, offensive midfielder; for, forward. 
Wednesday sessions, with reduced training loads on Thursdays and Fridays. Consequently on every Monday (post-match) and Wednesday CK concentrations reached higher levels than the respective Friday value, indicating lower muscle stress or greater in-week adaptation at the end of the week.

When interpreting results, the potential overlap of acute and chronic changes should be considered (Meister et al., 2014). The CK inter-day variability of the present study may be attributed to different external loads between each day and to the number of training sessions per day (Ehlers et al., 2002). CK accumulations after repeated load stimuli (Mohr et al., 2016) and muscular adaptions in the study progress (Brancaccio et al., 2010) can be further reasons for inter-day variability. The highest $\mathrm{CK}$ median of the present study (Wed3: $368 \mathrm{U} / \mathrm{L}$ ) may also demonstrate the relationship between various load stimuli and CK variations: one day before the blood sampling on Wed3, players completed two training sessions (total training duration: $105 \mathrm{~min}$ ) with $25 \mathrm{~min}$ of intense loading (Tables 2A,B). Additionally, three days before blood sampling a U-19 first league match took place, which may have also contributed to the $\mathrm{CK}$ accumulations (Mohr et al., 2016).

Alternation of match days between Saturday (test time: two days postmatch) and Sunday (one day postmatch) impacts $\mathrm{CK}$ responses on Mondays at the beginning of the training week, especially for the players with more than 45 min match participation. As seen in Tables 2A,B CK results after Sunday matches (on Mon2, Mon3, and Mon4) have shown higher values for the starting players compared to Saturday match days.

Overall, it seems that youth soccer players need approximately 24-48 $\mathrm{h}$ to recover after an official (Djaoui et al., 2016) or simulated match (Kunz et al., 2019). Thus, we recommend structuring the external load accordingly.

Urea inter-day variability is affected by load intensity and duration (Haralambie and Berg, 1976). Further influencing factors are fluid and protein intake (Hartmann and Mester, 2000), as well as the adaptation of protein metabolism to exercise. Moreover, urea accumulations after repeated load stimuli should be considered. In the present study, the highest urea median in $3-\mathrm{wk}_{\text {end }}$ (Fri5: $43 \mathrm{mg} / \mathrm{dL}$ ) was reached after three successive training days. As seen in Table 2, on each of these 3 days the players were exposed to exceptionally high training loads, and as mentioned earlier (Haralambie and Berg, 1976), the repetition of high training loads 3 days in a row most probably explains the elevated protein catabolism.

The CRP inter-day variability shown in this study can be explained by the differing load stimuli (Tables 2A,B) in the daily training routine (Chatzinikolaou et al., 2010). Further, elevated CRP concentrations could be a result of tissue damage derived from body contacts (Singh et al., 2011), partly explaining the observed CRP variability. Injury and illness (Vermeire et al., 2006), as well as personspecific characteristics like blood pressure and total cholesterol could potentially affect CRP values (Donges et al., 2010). impact CK responses on Mondays at the beginning of the training week. Especially CK results after Sunday matches (on
Mon2 and Mon3) have shown higher values compared to Saturday match days.

\section{Inter-Week Variability of CK, Urea, and CRP}

Considerable differences between CK, urea, and CRP responses were found in successive testing weeks (e.g., Wed1 vs. Wed2 vs. Wed3). To the best of our knowledge no other publication U-19 soccer players has examined the inter-week variability of selected biomarkers by frequent blood sampling. In the present study, periodical CK variations were shown in the first three testing weeks, which are most probably a result of the varying external loads as seen in Tables 2A,B. The CKkinetics in $3-\mathrm{wk}_{\text {mid }}$ reflected a certain periodization model planned by the coach's external load through increasing loads in three successive weeks. This observation is supported by elevated median values 3 weeks in a row based on the weekly average, and by the Wednesday results, showing that soccerspecific loads are sensitively reflected by the players' CK levels when frequent and dense measures are performed. In contrast, no periodical CK variations were shown in the last three testing weeks. This could be argued with the fact, that the weekly training plans in $3-\mathrm{wk}_{\text {end }}$ showed an altered structure compared to $3-\mathrm{wk}_{\mathrm{mid}}$. For instance, in $3-\mathrm{wk}_{\mathrm{end}}$ the days with no training sessions varied from week to week (Tue4, Sun5, Wed6, and Thu6).

Based on the present data we assume that CK concentrations reflect changes in the training load during a U-19 first league season. The relationship between the intended load management and the players' CK responses are confirmed by previous data (Malone et al., 2018) showing a relationship between systematically monitored CK concentrations and the expectable individual performance output in the following training sessions. Furthermore, we identified high correlations in $3-\mathrm{wk}_{\text {mid }}$ and $3-\mathrm{wk}_{\text {end }}$ between the mean daily $\mathrm{CK}$ and CRP values $(r=0.87 ; P=0.001$ and $r=0,64 ; P=0.12)$, which can be explained by the fact that muscle damage is often accompanied by local inflammatory responses (Singh et al., 2011).

Higher urea medians on Fri4 and Fri5 compared to Wed 4 and Wed5 were noticeable, indicating accumulated metabolic stress at the end of the week. One reason can be that in $3-\mathrm{wk}_{\text {end }}$ training loads were most intense on Wednesdays and Thursdays, which was consequently reflected in higher Friday values.

\section{Inter- and Intra-Individual Variability of CK, Urea, and CRP}

The present data demonstrates a large inter-individual variability of CK, urea, and CRP concentrations. Thus, we could verify the necessity of intra-individual reference values for interpreting parameter results. Universal soccer-specific reference values (Lazarim et al., 2009) are indeed useful for general classifications of results, but the validity is low for a player's individual stress assessment and the subsequent load management. Individualized interpretations have already been recommended for many years (Hartmann and Mester, 2000). 
The results of this study revealed a considerable intraindividual variability, clearly visible in the CVs of CK and CRP. The latter study identified CVs of $40 \%$ (CK), 13\% (urea), and 29\% (CRP), respectively. Sperlich et al. (2016) and Hartmann and Mester (2000) also found high interand intra-individual $\mathrm{CK}$ and urea variations in runners during a 3 -wk training camp, and in one athlete where the type of sport was unknown during a 4-wk training camp, respectively. The varying external loads shown in Tables 2A,B maybe one factor for the large inter- and intra-individual variability, because the concentrations were higher after days with high external loads compared to days with lower external loads. For instance, CK concentration on Mon2 (195 a.u., $337 \mathrm{U} / \mathrm{L}$ ) was higher compared to Mon5 (25 a.u., 152 $\mathrm{U} / \mathrm{L})$. In addition, the already discussed factors of interday variability, as well as person-specific characteristics may affect inter- and intra-individual $\mathrm{CK}$ variations, including individual physical performance levels (Ehlers et al., 2002), various player positions and the variably pronounced $\mathrm{CK}$ activity in high and low responders (Brancaccio et al., 2010) and of course the training load. Genetic predisposition is another factor (Meltzer, 1971) which may explain the variability. Inter- and intra-individual urea variability may be influenced by external factors (as discussed for inter-day variability) and by person-specific characteristics, including various player positions and the players' individual response behavior to physical strains.

\section{Practical Relevance}

Because of the practical advantages of this method (simple application, small sample volume, and rapid result reporting), POCT seems to be a practical method to monitor CK, urea, and CRP to judge high-performance U-19 players' individual physical stress responses. Internal biomarker analyses provide evidence for the recovery status of biological systems, which cannot be analyzed by other external monitoring procedures (e.g., heart rate measurement, GPS tracking, and subjective mood assessment). Consequently, in accordance with others (Wiewelhove et al., 2015), we recommend to combine markers representing various mechanisms contributing to fatigue, e.g., neuro-muscular performance measurements (i.e., jump performance) and perceived muscle fatigue (e.g., delayed onset of muscle soreness, DOMS).

Because CK, urea, and CRP showed a large inter-day variability we advise the assessment of all variables as frequently and densely as possible in order to identify trends in their kinetics. For this reason, our recommendation is not to assess the biomarkers within a (single) status diagnostic procedure but rather by frequent in-season monitoring. CK, urea, and CRP concentrations should be interpreted by intra-individual kinetics and not by general sport-specific cut-off references. The CK concentrations seem to respond sensitively to soccer-specific loads. CK concentrations offer interesting and additional information which can be utilized to optimize the soccer player's individual internal load, which may allow the prevention of fatigue-induced underperformances and injury.

Because CRP detectability in blood is shorter compared to that of $\mathrm{CK}$ (which is a practical disadvantage), and because CRP seems to be less sensitive than CK in reflecting external loading, our recommendation is not to frequently assess CRP levels. The possibility to assess CRP promptly and effortlessly with capillary blood is becoming increasingly important in connection with health screening in the event of complaints from athletes. Urea concentrations appear insufficient to claim valid inferences about the players' acute stress levels, therefore urea isn't an appropriate marker for the acute assessment of internal load but it could be an appropriate marker for assessing long-term (chronical) metabolic stress.

\section{Limitations}

Due to the players' training schedule more standardized time points for sampling were not feasible. In addition to the blood sampling the session ratings of perceived exertion (sRPE) method seems a valid method of quantitating exercise training during a wide variety of types of exercise (Foster et al., 2001). In the present investigation, the participants were among the top-ranked youth players in Germany, encountering a great amount of competitive stress. Participants are wanting to qualify for national team ranking or professional player status. In our experience and also mentioned elsewhere (Borg, 1998) highly motivated participants may underestimate perceived exertion in comparison with their individual work capacity. Since the aim of this study was to obtain objective variables, we refrained from employing the sRPE method.

\section{CONCLUSION}

Because of the high intra-individual variability of $\mathrm{CK}$, urea, and CRP concentrations, testing of CK, urea and CRP should be performed as frequently as possible in order to (i) understand the kinetics of each variable during a season in relation to the given training load, and (ii) generate meaningful consequences for training and match tactics. Our data showed lower CK values toward the end of the half season. Therefore, we conclude that CK should be assessed with individual reference values compared to the midpoint of the U-19 first league half season. CK sensitively reflected soccerspecific loads during our observation suggesting this variable as a promising biomarker for internal load estimation when assessed frequently.

\section{DATA AVAILABILITY STATEMENT}

The datasets generated for this study are available on request to the corresponding author. 


\section{ETHICS STATEMENT}

This study was approved by the ethics committee of the German Sport University (Cologne, Germany). Written informed consent to participate in this study was provided by the participants' legal guardian/next of kin.

\section{AUTHOR CONTRIBUTIONS}

All authors listed have made a substantial, direct and intellectual contribution to the work, and approved it for publication.

\section{REFERENCES}

Achtzehn, S., Broich, H., and Mester, J. (2018). "High-performance and elite sports in Point-of-Care testing: principles and clinical applications," in Point-of-Care Testing : Principles and Clinical Applications, eds P. B. Luppa and H. Schlebusch (Berlin: Springer).

Ascensao, A., Rebelo, A., Oliveira, E., Marques, F., Pereira, L., and Magalhaes, J. (2008). Biochemical impact of a soccer match analysis of oxidative stress and muscle damage markers throughout recovery. Clin. Biochem. 41, 841-851. doi: 10.1016/j.clinbiochem.2008. 04.008

Banfi, G., Colombini, A., Lombardi, G., and Lubkowska, A. (2012). Metabolic markers in sports medicine. Adv. Clin. Chem. 56, 1-54. doi: 10.1016/b978-012-394317-0.00015-7

Borg, G. (1998). Borg's Perceived Exertion and Pain Scales. Champaign, IL: Human kinetics.

Brancaccio, P., Lippi, G., and Maffulli, N. (2010). Biochemical markers of muscular damage. Clin. Chem. Lab. Med. 48, 757-767.

Brink, M. S., Visscher, C., Arends, S., Zwerver, J., Post, W. J., and Lemmink, K. A. (2010). Monitoring stress and recovery: new insights for the prevention of injuries and illnesses in elite youth soccer players. Br. J. Sports Med. 44, 809-815. doi: $10.1136 /$ bjsm.2009.069476

Chatzinikolaou, A., Fatouros, I. G., Gourgoulis, V., Avloniti, A., Jamurtas, A. Z., Nikolaidis, M. G., et al. (2010). Time course of changes in performance and inflammatory responses after acute plyometric exercise. J. Strength Cond. Res. 24, 1389-1398. doi: 10.1519/jsc.0b013e3181 d $1 \mathrm{~d} 318$

de Hoyo, M., Cohen, D. D., Sanudo, B., Carrasco, L., Alvarez-Mesa, A., Del Ojo, J. J., et al. (2016). Influence of football match time-motion parameters on recovery time course of muscle damage and jump ability. J. Sports Sci. 34, 1363-1370. doi: 10.1080/02640414.2016.11 50603

Djaoui, L., Diaz-Cidoncha Garcia, J., Hautier, C., and Dellal, A. (2016). Kinetic post-match fatigue in professional and youth soccer players during the competitive period. Asian J. Sports Med. 7:e28267.

Donges, C. E., Duffield, R., and Drinkwater, E. J. (2010). Effects of resistance or aerobic exercise training on interleukin-6, C-reactive protein, and body composition. Med. Sci. Sports Exerc. 42, 304-313. doi: 10.1249/mss. $0 \mathrm{~b} 013 \mathrm{e} 3181 \mathrm{~b} 117 \mathrm{ca}$

Ehlers, G. G., Ball, T. E., and Liston, L. (2002). Creatine kinase levels are elevated during 2-A-day practices in collegiate football players. J. Athl. Train. 37, 151156.

Fatouros, I. G., Chatzinikolaou, A., Douroudos Ii Nikolaidis, M. G., Kyparos, A., Margonis, K., Michailidis, Y., et al. (2010). Time-course of changes in oxidative stress and antioxidant status responses following a soccer game. J. Strength Cond. Res. 24, 3278-3286. doi: 10.1519/jsc.0b013e3181b 60444

Foster, C., Florhaug, J. A., Franklin, J., Gottschall, L., Hrovatin, L. A., Parker, S., et al. (2001). A new approach to monitoring exercise training. J. Strength Cond. Res. 15, 109-115.

\section{FUNDING}

This publication was supported by the Open Access Publication Fund of the University of Würzburg.

\section{ACKNOWLEDGMENTS}

The authors thank the players and the club staff for their participation and the Roche Diagnostics $\mathrm{GmbH}$ which supplied test devices and consumables for free.

Haralambie, G., and Berg, A. (1976). Serum urea and amino nitrogen changes with exercise duration. Eur. J. Appl. Physiol. Occup. Physiol. 36, 39-48. doi: $10.1007 / \mathrm{bf} 00421632$

Hartmann, U., and Mester, J. (2000). Training and overtraining markers in selected sport events. Med. Sci. Sports Exerc. 32, 209-215.

Ispirlidis, I., Fatouros, I. G., Jamurtas, A. Z., Nikolaidis, M. G., Michailidis, I., Douroudos, I., et al. (2008). Time-course of changes in inflammatory and performance responses following a soccer game. Clin. J. Sport Med. 18, 423-431. doi: 10.1097/jsm.0b013e3181 $818 \mathrm{e} 0 \mathrm{~b}$

Julian, R., Meyer, T., Fullagar, H. H., Skorski, S., Pfeiffer, M., Kellmann, M., et al. (2017). Individual patterns in blood-borne indicators of fatigue-trait or chance. J. Strength Cond. Res. 31, 608-619. doi: 10.1519/jsc.0000000000 001390

Kunz, P., Zinner, C., Holmberg, H. C., and Sperlich, B. (2019). Intra- and post-match time-course of indicators related to perceived and performance fatigability and recovery in elite youth soccer players. Front. Physiol. 10:1383. doi: $10.3389 /$ fphys.2019.01383

Lazarim, F. L., Antunes-Neto, J. M., Da Silva, F. O., Nunes, L. A., BassiniCameron, A., Cameron, L. C., et al. (2009). The upper values of plasma creatine kinase of professional soccer players during the Brazilian National Championship. J. Sci. Med. Sport 12, 85-90. doi: 10.1016/j.jsams.2007. 10.004

Malone, S., Mendes, B., Hughes, B., Roe, M., Devenney, S., Collins, K., et al. (2018). Decrements in neuromuscular performance and increases in creatine kinase impact training outputs in elite soccer players. J. Strength Cond. Res. 32, 1342-1351. doi: 10.1519/jsc.00000000000 01997

Meister, S., Aus Der Funten, K., and Meyer, T. (2014). Repeated monitoring of blood parameters for evaluating strain and overload in elite football players: is it justified? J. Sports Sci. 32, 1328-1331. doi: 10.1080/02640414.2014.92 7070

Meltzer, H. Y. (1971). Factors affecting serum creatine phosphokinase levels in the general population: the role of race, activity and age. Clin. Chim. Acta 33, 165-172. doi: 10.1016/0009-8981(71)90 264-6

Mohr, M., Draganidis, D., Chatzinikolaou, A., Barbero-Alvarez, J. C., Castagna, C., Douroudos, I., et al. (2016). Muscle damage, inflammatory, immune and performance responses to three football games in 1 week in competitive male players. Eur. J. Appl. Physiol. 116, 179-193. doi: 10.1007/s00421-015-3 245-2

Nedelec, M., Mccall, A., Carling, C., Legall, F., Berthoin, S., and Dupont, G. (2012). Recovery in soccer: part I - post-match fatigue and time course of recovery. Sports Med. 42, 997-1015. doi: 10.1007/bf032 62308

Pepys, M. B., and Hirschfield, G. M. (2003). C-reactive protein: a critical update. J. Clin. Invest. 111, 1805-1812. doi: 10.1172/jci20031 8921

Pfirrmann, D., Herbst, M., Ingelfinger, P., Simon, P., and Tug, S. (2016). Analysis of injury incidences in male professional adult and elite youth soccer players: 
a systematic review. J. Athl. Train. 51, 410-424. doi: 10.4085/1062-605051.6.03

Romagnoli, M., Sanchis-Gomar, F., Alis, R., Risso-Ballester, J., Bosio, A., Graziani, R. L., et al. (2016). Changes in muscle damage, inflammation, and fatiguerelated parameters in young elite soccer players after a match. J. Sports Med. Phys. Fitness 56, 1198-1205.

Rosenthal, R. (1994). "Parametric measures of effect size," in The Handbook of Research Synthesis, (New York, NY: Russell Sage Foundation), 231-244.

Singh, T. K., Guelfi, K. J., Landers, G., Dawson, B., and Bishop, D. (2011). A comparison of muscle damage, soreness and performance following a simulated contact and non-contact team sport activity circuit. J. Sci. Med. Sport 14, 441-446. doi: 10.1016/j.jsams.2011. 03.008

Sperlich, B., Achtzehn, S., De Marees, M., Von Papen, H., and Mester, J. (2016). Load management in elite German distance runners during 3weeks of high-altitude training. Physiol. Rep. 4:e12845. doi: 10.14814/phy2. 12845

Starling, L. T., and Lambert, M. I. (2018). Monitoring rugby players for fitness and fatigue: what do coaches want? Int. J. Sports Physiol. Perform. 13, 777-782. doi: 10.1123/ijspp.2017-0416
Thorpe, R., and Sunderland, C. (2012). Muscle damage, endocrine, and immune marker response to a soccer match. J. Strength Cond. Res. 26, 2783-2790. doi: 10.1519/jsc.0b013e318241e174

Vermeire, S., Van Assche, G., and Rutgeerts, P. (2006). Laboratory markers in IBD: useful, magic, or unnecessary toys? Gut 55, 426-431. doi: 10.1136/gut.2005. 069476

Wiewelhove, T., Raeder, C., Meyer, T., Kellmann, M., Pfeiffer, M., and Ferrauti, A. (2015). Markers for routine assessment of fatigue and recovery in male and female team sport athletes during high-intensity interval training. PLoS One 10:e0139801. doi: 10.1371/journal.pone.0139801

Conflict of Interest: The authors declare that the research was conducted in the absence of any commercial or financial relationships that could be construed as a potential conflict of interest.

Copyright (c) 2020 Becker, Sperlich, Zinner and Achtzehn. This is an open-access article distributed under the terms of the Creative Commons Attribution License (CC BY). The use, distribution or reproduction in other forums is permitted, provided the original author(s) and the copyright owner(s) are credited and that the original publication in this journal is cited, in accordance with accepted academic practice. No use, distribution or reproduction is permitted which does not comply with these terms. 